\title{
Anti-angiogenic strategies and vascular targeting in the treatment of lung cancer
}

\author{
C.S. Brock, S.M. Lee
}

\begin{abstract}
Anti-angiogenic strategies and vascular targeting in the treatment of lung cancer. C.S. Brock, S.M. Lee. C) ERS Journals Ltd 2002.

ABSTRACT: The generation of new blood vessels, angiogenesis, is important for tumour proliferation and metastasis. This involves a number of interacting processes and factors, such as growth factors and the receptor tyrosine kinases, matrix metalloproteinases and integrins.

Studies have shown that tumour vascularity and the overexpression of growth factors and their receptors are of independent prognostic importance in different cancers, including lung cancer.

The present article provides a background to angiogenesis and describes the potential targets for anti-angiogenic and vascular targeting strategies in cancer, focusing specifically on carcinoma of the lung. It also describes the anti-angiogenic drugs presently under phase I, II and III investigation and highlights some of the problems associated with the standard methodologies for assessing tumour response and drug efficacy using these agents.
\end{abstract}

Eur Respir J 2002; 19: 557-570.
Meyerstein Institute of Oncology, Middlesex/University College London Hospitals, Mortimer Street, London, UK.

Correspondence: C.S. Brock, CRC Centre for Cancer Therapeutics, The Institute of Cancer Research, Block E, Cotswold Road, Belmont, Sutton, Surrey, SM2 5NG, UK. Fax: 442086427979 E-mail: cbrock@icr.ac.uk

Keywords: Anti-angiogenesis, lung cancer, vascular targeting

Received: November 72001

Accepted: November 272001
Lung cancer is the most common cause of cancerrelated death, accounting for $\sim 29,500$ deaths per annum (1999) [1]. In general, patients present in their 6 th or 7 th decades, and both cigarette smoking and asbestos exposure are the two main risk factors for its development. For years it has been the most common cause of male cancer death, although this incidence appears to be falling, whereas it is increasing in females [2], probably due to changing smoking habits.

Over $80 \%$ of cases are nonsmall cell lung cancer (NSCLC), of which $40 \%$ are adenocarcinoma, 30\% squamous cell carcinoma and $10-15 \%$ large cell cancers. Small cell lung cancer (SCLC) accounts for the remaining $20 \%$. Currently available treatments include surgery for operable NSCLC, which offers the best chance of cure. However, $<50 \%$ of patients are cured, perhaps due to the presence of occult local or metastatic disease at the time of surgery. The addition of the functional imaging technique of $\left({ }^{18} \mathrm{~F}\right)$ fluoro-deoxyglucose-positron emission tomography to the staging investigations may upstage or downstage disease, thereby sparing patients unnecessary surgery or allowing potentially curative surgery [3-5]. Combination platinum-based chemotherapy and radiotherapy regimens are frequently used to treat inoperable NSCLC. Newer chemotherapeutic agents, such as gemcitabine, vinorelbine and the taxanes, docetaxel and paclitaxel, are increasingly being used to treat advanced NSCLC. Despite the emergence of these new agents, there has been no significant breakthrough in improving the prognosis of these patients.

Outcomes for SCLC are equally limited. Despite the high response rates achieved following chemotherapy, the majority of patients will die from disease progression either locally, at distant sites, or both.

Since tumour growth and metastasis are angiogenesisdependent, relying upon the generation of new blood vessels to sustain proliferation, survival and spread of the malignant cells, therapeutic strategies aimed at inhibiting angiogenesis are theoretically attractive. Recent advances in histopathological and molecular biological assays have given rise to prognostic indicators for survival with the potential of novel molecular targets. The investigation and development of different anti-angiogenesis and vascular targeting strategies are of interest with respect to numerous tumour types, including lung carcinoma.

Previous articles in this series: No. 1: Steels E, Paesmans M, Berghmans T, et al. Role of p53 as a prognostic factor for survival in lung cancer: a systematic review of the literature with a meta-analysis. Eur Respir J 2001; 18: 705-719. No. 2: van Klaveren RJ, Habbema JDF, Pedersen JH, de Koning HJ, Oudkerk M, Hoogsteden HC. Lung cancer screening by low-dose spiral computed tomography. Eur Respir J 2001; 18: 857-866. No. 3: Brambilla E, Travis WD, Colby TV, Corrin B, Shimosato Y. The new World Health Organization classification of lung tumours. Eur Respir J 2001; 18: 1059-1068. 


\section{Angiogenesis}

Following the description by FoLKMAN [6] that the growth of solid tumours is dependent upon their ability to elicit the development of new blood vessels into the tumour mass (angiogenesis), there has been an increasing interest in attempts to target tumour vasculature in order to inhibit tumour growth. Initially, tumours utilize the existing host vasculature, but in order to sustain continued growth, new vessel formation is necessary to supply nutrients for tumour cellular proliferation. Endothelial cell activation results in the production of matrix metalloproteinases (MMPs), which break down the surrounding extracellular matrix, permitting the dividing endothelial cells to develop into new blood vessels.

The angiogenic potential of the endothelial cell is carefully balanced between positive and negative regulation. Tumours have the potential of up- or downregulating these controls, producing an environment in which new blood vessel formation (neoangiogenesis) occurs, and thereby supporting tumour growth. Examples of factors that stimulate and inhibit angiogenesis are given in table 1.

Angiostatin, an internal fragment of plasminogen, is a specific inhibitor of endothelial cell proliferation. It was isolated in the sera and urine of tumour-bearing mice after they were shown to inhibit endothelial cell proliferation. This effect was neither seen with the sera nor urine obtained from control mice [7]. A recentlyreported phase I study of recombinant angiostatin in patients with advanced cancers showed there to be no dose-limiting toxicity with linear pharmacokinetics. A transient maculopapular rash was seen in four of 15 patients. There was a $15-92 \%$ reduction in urine basic fibroblast growth factor (bFGF) levels in seven of 15 patients and a 30-60\% reduction in urine vascular endothelial growth factor (VEGF) levels in five of 10 patients [8].

A recent immunohistochemistry study of 143 primary NSCLCs demonstrated that the median survival of patients with angiostatin-negative/VEGFpositive tumours was significantly less (52 weeks), compared to those with angiostatin-positive/VEGFnegative tumours (184 weeks). Therefore, it has been suggested that the balance of angio-promoting and

Table 1. - Some of the factors involved in tumour angiogenesis

Factors affecting angiogenesis

\begin{tabular}{lc}
\hline Stimulators (angiogenic) & Inhibitors (angiostatic) \\
\hline VEGF & Angiostatin \\
a- and b-FGF & Endostatin \\
EGF & TGF- $\beta$ \\
TNF- $\alpha$ & TIMPs \\
Integrins & \\
\hline
\end{tabular}

VEGF: vascular endothelial growth factor; EGF: endothelial growth factor; FGF: fibroblast growth factor (a-acidic and b-basic); TNF- $\alpha$ : tumour necrosis factor- $\alpha$; TGF- $\beta$ : transforming growth factor- $\beta$; TIMPs: tissue inhibitors of metalloproteinases. angio-inhibiting factors plays a crucial role in the control of tumour growth [9].

Endostatin is a C-terminal fragment of collagen XVIII. In a similar manner to angiostatin, it is a natural circulating anti-angiogenic molecule with potent antitumour effects in experimental models and is activated only after proteolytic conversion [10]. Trials are ongoing to assess endostatin in patients with advanced cancer.

\section{Neo-angiogenesis and lung cancer}

\section{Intratumoural microvessel density}

Microvessel density (MVD) is a semiquantitative surrogate measure of angiogenesis. The microvessels are immunohistochemically stained using endothelial cell-specific antibodies, such as anti-CD31, anti-CD34 and anti-Factor VIII-related antigen. The MVD of the stained sections can be measured using Chalkley point counting [11]. This method involves subjectively determining the most vascular tumour areas at low magnification using a light microscope. At higher power, a 25-point Chalkley eyepiece graticule is applied to each vascular "hot spot" area and rotated so that a maximum number of points of the grid are on, or within, the vessels. These overlying points give the Chalkley count. The average counts from the assessments of three tumour hot spots produce the Chalkley scores for the intratumoural microvessel density (IMD) [11]. This method of quantitation formed part of the International Consensus on the methodology of quantitation of angiogenesis [12].

A number of studies have shown that increased tumour MVD relative to that of normal tissue is associated with a poorer prognosis. IMD has been shown to be an independent prognostic indicator in breast cancer [13-15] and bladder cancer [16]. It has also been found to correlate with metastases in breast, colon and prostate cancers [17-19].

Similarly, for NSCLC, IMD has been shown to be an independent prognostic factor. In several studies, a high IMD has been associated with a poorer prognosis [20-23] or risk of a relapse [24] in patients with operable NSCLC. MATSUYAMA et al. [21] demonstrated that high IMD was significantly related to haematogenous spread, but not nodal metastases. Thus, it has been suggested that IMD may indicate an aggressive tumour, thereby providing a potential method with which to select those patients requiring adjuvant therapy.

However, it should be noted that not all studies have demonstrated a relationship between IMD and prognosis in NSCLC. In a group of 88 patients, with a follow-up period of $\geqslant 5 \mathrm{yrs}$, CHANDRACHUD et al. [25] demonstrated that vascularity was not associated with patient age, tumour type, volume, size, stage, nodal status or survival. In another study of 500 patients with stage I NSCLC, four patterns of vascularity were identified. Three patterns (basal, papillary, diffuse) involved destruction of the normal lung with production of neovasculature and stroma. 
The fourth pattern (alveolar) was putatively nonangiogenic and was characterized by lack of parenchymal destruction with the absence of new stroma and vessels. The study concluded that if an appropriate vascular bed is available, then the tumour can exploit it without angiogenesis. This is of interest when investigating the targeting of vasculature as a therapeutic manoeuvre [26].

In human SCLC tumour xenografts, it has been shown that a positive correlation existed between vascular density and VEGF protein expression, whereas there was a negative correlation between vascular density and bFGF expression. The differing results suggest that IMD is useful for determining biological information regarding the tumour, but that it should not be used primarily for prognostic purposes [27].

\section{Targets for anti-angiogenesis}

Neo-angiogenesis is a complicated process providing a number of potential targets to inhibit tumour proliferation. These targets include the growth factors and the receptor tyrosine kinases, as well as the MMPs and integrins.

\section{Receptor tyrosine kinases}

Growth factors and receptor tyrosine kinases are involved in the endothelial cell proliferation and migration, thus making them important regulators of angiogenesis.

Binding of the growth factor to the transmembrane receptor tyrosine kinases initiates the signalling transduction cascade interaction with the cell regulatory pathways, thereby stimulating physiological processes promoting cellular proliferation.

Vascular endothelial growth factor and its receptors. VEGF, also known as vascular permeability factor, is a dimeric protein expressed in tissues undergoing angiogenesis, whether in normal or abnormal physiological states [28]. Its action on the endothelial cell produces regulation of permeability as well as proliferation, which are mediated through the receptor tyrosine kinases, VEGF receptor (VEGFR)/fms-like tyrosine kinase 1 (VEGFR-1) and foetal liver kinase-1 (Flk-1)/kinase insert domain containing receptor (KDR) (VEGFR-2).

Amplification or mutation of oncogenes, such as v-Ha ras, v-raf, k-ras, fos, src, neu, have been shown to activate or upregulate VEGF [29-33]. In addition, induction of VEGF messenger ribonucleic acid (mRNA) expression can result from hypoxia [34] and transforming growth factor (TGF)- $\beta$ [35]. Since a number of unrelated alterations in cellular regulation can result in VEGF upregulation, it has been suggested that this may be a final common pathway for in vivo proliferation.

VEGF is one of a family of vascular endothelial growth factors: VEGF, VEGF-B, VEGF-C, VEGF-D. Different VEGF isoforms also exist, such as $\mathrm{VEGF}_{121}, \mathrm{VEGF}_{165}, \mathrm{VEGF}_{189}$ and $\mathrm{VEGF}_{206}$. The predominant isoform secreted is $\mathrm{VEGF}_{165}$, although a recent study has proposed that the expression of the VEGF $_{189}$ mRNA isoform is an independent prognostic variable in survival and postoperative relapse for patients with NSCLC [36].

Tumour overexpression of VEGF and VEGFR has also been shown to be of independent prognostic significance in a number of solid tumours [37-43], including lung cancer [44-47].

In a study of 104 patients with operable stage I NSCLC, it was found that the primary tumour specimens obtained from patients with relapsed disease $(n=43)$ had a higher mean VEGF antigen staining and IMD than the primary tumour specimens obtained from those patients who did not relapse from their disease $(n=61)$. It was concluded that VEGF expression and IMD may help to predict risk of recurrence [48]. Although, it has been shown that VEGF measurement alone is not of prognostic significance, it may be of use in conjunction with MVD [49].

As well as determining tissue and tumour VEGF mRNA expression, it is possible to measure VEGF concentrations in bodily fluids. In patients with lung cancer, serum VEGF concentrations can increase with tumour stage progression [50], and for patients with SCLC, elevated serum VEGF concentrations at the time of diagnosis can be associated with a poorer response to therapy and a worse survival rate [51]. However, not all studies have demonstrated this relationship. In one, elevated bFGF levels were correlated with a good prognosis in NSCLC and no correlation was seen with serum VEGF concentrations [52]. VEGF concentrations have also been measured in bronchoalveolar lavage fluid (BALF). Raised concentrations have been seen in patients with advanced NSCLC before and during treatment. Higher levels were seen in patients receiving radiotherapy prior to chemotherapy, perhaps suggesting that BALF levels of VEGF are affected by tumour activity and treatment-related oxidative stress [53].

These findings offer the opportunity to measure VEGF concentrations, not only to investigate its role as a surrogate measure for prognostic purposes, but perhaps also to follow changes in VEGF concentrations during the course of the patient's disease with different therapeutic interventions in order to predict efficacy.

Platelet-derived growth factor. The platelet-derived growth factor (PDGF) receptor may also play a role in angiogenesis. PDGF is a pleiotropic factor that exists as a hetero- or homodimer of 2 two polypeptides, A- and B-chains [54]. PDGF ligands interact with two receptor subtypes, receptors $\alpha$ and $\beta$. PDGF receptors are expressed on tumour neovasculature and upregulated during tumour progression. Both PDGF and its receptors have been detected in different tumour types, and some studies suggest it may predict for a poorer prognosis [55-57].

Tie-1, Tie-2 and the angiopoietins. Tie-1 and Tie-2 are relatively newer receptor tyrosine kinases. They are expressed specifically in developing endothelial cells. The function of Tie-1 is unknown, although studies 
have shown that Tie-1 is important for differentiation of endothelial cells and the integrity of blood vessels. Tie-2 appears to be involved in the angiogenic processes of the endothelial cells [58]. The receptor ligands for Tie-2 are angiopoietin (Ang)-1 and Ang-2. It appears that Ang-1 is an angiogenic factor and an agonist to Tie-2, whereas Ang-2 is an antagonist. In humans, Ang-2 is only expressed at sites of vascular remodelling [59].

In a study of 32 primary NSCLC samples and paired adjacent lung tissue, it was demonstrated that levels of Tie-2, Ang-1, VEGF and CD31 mRNAs were higher in the cancers than the adjacent normal lung tissue, suggesting that Ang-1 may also be an important angiogenic factor in human NSCLC [60]. In a similar study of 28 pairs of primary NSCLC and normal lung tissue, a significant upregulation of VEGF expression was seen by tumour cells. There was also increased intensity of Ang-2 expression in the tumour blood vessels, whereas the adjacent normal lung tissue constitutively expressed high levels of Ang-1 and Tie-2 [61].

Platelet-derived endothelial cell growth factor. Plateletderived endothelial cell growth factor (PDEC-GF) is a growth factor which has been shown to have thymidine phosphorylase (TP) activity (PDEC-GF/TP) [62]. Thymidine catabolism may increase the cancer cell secretion of interleukin-8, VEGF and MMP1, which are known to be induced by oxidative stress [63]. PDEC-GF has been shown to stimulate chemotaxis and angiogenesis in tumour models in vitro $[63,64]$ and in vivo [65-69]. Recently, it was shown to play an important role in angiogenesis in NSCLC [46].

In 107 patients with operable NSCLC, increased PDEC-GF/TP expression correlated with a higher vascular grade. On subset analysis, those patients with node-negative disease and overexpression of PDECGF/TP had a poorer prognosis [70].

YAMASHITA et al. [71] demonstrated an eight-fold lower mean concentration of PDEC-GF/TP in tumour extracts from SCLC, as opposed to those obtained from NSCLC tumours. These authors postulated that different pathways for tumour angiogenesis were utilized by the different types of lung cancer.

Fibroblast growth factors. The family of fibroblast growth factors (FGF) includes bFGF (FGF-2), which has the potential to stimulate angiogenesis. This growth factor family is related to heparin-binding growth factors, and there have been reports of overexpression in lung cancer patients [72].

Basic FGF concentrations were measured in a study of 37 patients with benign inflammatory pleural disease, peripheral lung adenocarcinoma or mesothelioma serum and pleural effusion. The bFGF concentrations in the pleural effusions were significantly lower in the mesothelioma group in comparison with the benign inflammatory pleural disease group. There was an inverse correlation between the pleural effusion bFGF concentrations and patient survival in the mesothelioma group. High serum bFGF levels correlated with a poorer survival, but no relationship was demonstrated between bFGF concentration and IMD [73]. However, in a study of 206 patients with NSCLC, while patients with high FGF receptor-1 expression had a significantly shorter survival, there was no significant correlation between bFGF expression and survival [74].

In human SCLC xenografts, a positive correlation was demonstrated between tumour vessel density and VEGF protein expression, but a strong negative correlation was found between vessel density and tissue bFGF expression [28]. In 106 patients with NSCLC, serum bFGF levels did not differ between clinical stages [75]. In a study of 68 patients with NSCLC, no correlation was seen between serum VEGF levels and prognosis, yet it was found that elevated bFGF levels conferred a good prognosis [52]. In contrast, for patients with SCLC $(n=46)$, a significant difference was found in serum bFGF levels between patients with chemo-responsive and non-responsive tumours [75].

Epidermal growth factor, epidermal growth factor receptors and transforming growth factor- $\alpha$. The epidermal growth factor (EGF) and its receptors (EGFRs) are currently attracting a lot of attention due to the ongoing studies of Herceptin (Trastuzimab) (Genentech, Inc., South San Francisco, CA, USA), a human EGF receptor HER2-neu monoclonal antibody, in breast cancer.

The EGFRs are a receptor family consisting of EGFR (HER1/c-erbB1), HER2 (c-erbB2), HER3 (c-erbB3), HER4 (c-erbB4). The activation of EGFR by extracellular ligand binding is predominantly by EGF and TGF- $\alpha[76,77]$. Ligand binding leads to dimerization of the EGFRs, which, via autophosphorylation, activate cell signalling and the pathways leading to cellular proliferation, angiogenesis and metastasis. TGF- $\alpha$ is, in fact, produced by normal as well as abnormal cells. Co-expression of EGFR and its ligand TGF- $\alpha$ has been shown to have a strong correlation with IMD and has been proposed to form an autocrine loop [78]. However, none of these receptors have been linked directly with angiogenesis [28] and it has been suggested that EGF acts indirectly by the induction of VEGF [79], thereby promoting angiogenesis.

Overexpression of EGFR occurs in a number of tumour types, including breast cancer [80] and lung cancer [81]. Whereas the prognostic roles of EGFR and HER2-neu in breast cancer are more clearly understood, they remain less clear for NSCLC. Some studies demonstrated high HER2-neu expression with poor survival and an additive impact upon survival with co-expression of HER2-neu and EGFR [82], whereas others have shown that amplification of the erbB family in NSCLC patients has little prognostic significance [83]. Overexpressions of EGFR and TGF- $\alpha$ have frequently been seen in early-stage NSCLC, but were found to have no prognostic value [84].

The role of HER2-neu monoclonal antibody in the treatment of lung cancer is currently under investigation. 
Tissue inhibitors of matrix metalloproteinases and matrix metalloproteinase inhibitors

MMPs are zinc-dependent proteinases that degrade the extracellular matrix. In normal physiological conditions, they are involved in healing, but they also play a role in the pathogenesis of arthritis and tumour invasiveness, angiogenesis and metastasis. Currently, 20 enzymes have been identified and are classified as MMPs. These have recently been reviewed [85].

Naturally-occurring tissue inhibitors of metalloproteinases have been identified, upon which synthetic matrix metalloproteinase inhibitors (MMPIs) have been based. Studies with synthetic MMPIs, such as batimastat, have suggested that inhibition of angiogenesis occurs as well as a reduction in metastatic potential [86]. Studies with MMPIs are ongoing in lung cancer.

\section{Integrins}

The integrin family are multifunctional cell adhesion molecules that are composed of noncovalently associated $\alpha$ and $\beta$ chains. These combine to produce numerous heterodimers with different properties. They regulate a variety of cellular responses, such as adhesion, migration, invasion, proliferation, survival and apoptosis. Overexpression of $\alpha_{2}, \alpha_{5}, \beta_{1}$ and $\beta_{3}$ integrins can arise from stimulation by bFGF, and TGF- $\beta$ can stimulate expression of the above, except $\beta_{3}$ [87]. It has been shown that in normal quiescent blood vessels $\alpha_{v} \beta_{3}$ integrin is minimally expressed, but during angiogenesis in vivo, it is significantly upregulated [88].

Vitaxin (Applied Molecular Evolution, Inc., San Diego, CA, USA) is a humanized monoclonal antibody directed at $\alpha_{v} \beta_{3}$ integrin. It has completed Phase I investigation in patients with stage IV tumours and little toxicity was seen, apart from infusion-related fever. Of the 14 evaluable patients, one had a partial response and disease stabilization was seen in a further seven patients. Two of the patients had NSCLC, one progressed through treatment and one patient was not evaluable [89].

Other inhibitors of integrins are currently under phase I investigation in solid tumours.
For numerous solid tumours, including lung cancer, targets associated with angiogenesis have been described and shown to be of prognostic importance. These findings have further fuelled the interest in anti-angiogenic and vascular targeting as therapeutic anticancer strategies.

\section{Anti-angiogenic strategies}

The targeting and damaging of a single blood vessel can potentially kill thousands of tumour cells, as has been performed by embolization of feeding vessels in tumours such as hepatomas. It had been thought that the tumour neovasculature, being tortuous and leaky with arteriovenous pooling, may not allow adequate drug delivery. Targeting the vessels has a potential advantage in that endothelial cells are adjacent to the blood stream, which circumvents the potential of delivery problems.

It has also been suggested that since normal dividing endothelial cells are targeted, as opposed to tumour cells, the development of drug resistance may not evolve and has not been seen, as yet, in long-term animal studies or preliminary clinical studies. The anti-angiogenesis and vascular targeting strategies, therefore, may not result in tumour cell kill, but may maintain "stable disease". This has given rise to the term "cytostatic paradigm" [90], where control of the cancer phenotype is obtained without eradication.

The following generic approaches for targeting tumour vasculature currently exist: 1) destroying existing blood vessels (vascular targeting); and 2) preventing the development of tumour neovasculature (anti-angiogenesis)

As previously discussed, there are numerous interacting processes involved in angiogenesis, some having provided targets for possible therapeutic interventions. Those currently pertinent to lung cancer are discussed in the following sections.

\section{Drugs that cause direct inhibition of the endothelial cell}

This section will specifically focus on drugs that inhibit the endothelial cell (table 2). They fulfil the term "vascular-targeting" strategies, which aim to produce extensive cell death by damaging microvascular function and generate vessel occlusion [91].

Table 2.-Recent phase I, II and III trials of drugs inhibiting endothelial cells recruiting in the USA

\begin{tabular}{|c|c|c|}
\hline Drug and trial & Tumour type & Target/mechanism \\
\hline Thalidomide $\#$ & & \multirow[t]{3}{*}{ Unknown } \\
\hline Phase III & $\begin{array}{l}\text { Carboplatin, paclitaxel and radiotherapy }+/- \\
\text { thalidomide in stage III NSCLC (active) }\end{array}$ & \\
\hline Phase II & $\begin{array}{l}\text { Carboplatin, irinotecan and thalidomide in stage } \\
\text { IIIB or IV NSCLC (approved not yet active) }\end{array}$ & \\
\hline Endostatin & & \\
\hline Phase I & Advanced refractory solid tumours (completed September 2001) & \multirow[t]{2}{*}{ Inhibition of endothelial cells } \\
\hline Phase I & Advanced solid tumours (closed August 2001) & \\
\hline
\end{tabular}

NSCLC: nonsmall cell lung cancer. ${ }^{\#}$ : commercially available; approval for leprosy. Manufacturer's details are as follows: thalidomide: Celgene Corp., Warren, NJ, USA; Endostatin: EntreMed, Inc., Rockville, MD, USA. 
Thalidomide. The mechanism of action of thalidomide (Celgene Corporation, Warren, New Jersey, USA) is poorly understood. The interactions include tumour necrosis factor- $\alpha$ inhibition, lowering of cytokines and VEGF and a variety of effects upon the immune system and cell surface receptors to inhibit angiogenesis $[92,93]$. It has been shown that thalidomide reduces the incidence of lung metastases from primary Lewis lung tumours [93]. Responses have been observed in patients receiving thalidomide for the treatment of Kaposi's sarcoma $(40 \%)$ [94] and glioma (16 of 36) [95]. The most serious toxicity of thalidomide is that of teratogenicity, otherwise the other side-effects reported are nausea, neutropenia, rash, reversible sensory neuropathy, dizziness and dose-dependent somnolence.

A phase II study of thalidomide in stage IIIB and IV NSCLC has recently been approved, with thalidomide being administered in combination with carboplatin and paclitaxel. A phase III trial randomizing patients with stage III NSCLC to receive carboplatin, paclitaxel and radiotherapy with or without thalidomide is presently recruiting. A further study of thalidomide in combination with carboplatin and etoposide chemotherapy in SCLC is presently recruiting patients under the auspices of the Cancer Research Campaign. The aim of administering thalidomide as maintenance therapy is to delay the onset of tumour relapse.

Squalamine. Squalamine (Genaera Corporation, Plymouth Meeting, PA, USA) is a naturallyoccurring anti-angiogenic aminosterol derived from the liver of the dogfish shark, which inhibits the sodium-hydrogen exchanger and increases tumour oxygenation. Squalamine, administered subcutaneously to murine Lewis lung tumours, increased the tumour growth delays produced by cyclophosphamide, cisplatin, paclitaxel and 5-fluorouracil 2.4-3.8fold versus chemotherapy alone. Squalamine alone also reduced the number of lung metastases occurring [96]. In vitro, in human lung tumour xenografts (H460), the combination of squalamine with paclitaxel, vinorelbine, gemcitabine and docetaxel showed no enhancement of antitumour activity on tumour angiogenesis. However, when used in combination with cisplatin, a $25 \%$ reduction in CD31 vessel formation was detected [97].

Two phase I studies assessing squalamine have reported preliminary results. Squalamine was administered as a 5-day continuous infusion repeated every 3 weeks, and the second phase I study increased the duration of the infusion from 5 days to a maximum of 30 days, once the dose-limiting toxicity had occurred. The drug was well tolerated, with no grade 3 or 4 toxicities, except reversible transaminitis and fatigue. No objective tumour responses were seen $[98,99]$.

Additional studies assessing squalamine in both SCLC and NSCLC are planned in the future.

Endostatin. Preliminary results of a phase I study of recombinant endostatin in 22 patients with solid tumours have been published. There was a significant reduction in tumour blood flow at 56 days, as measured with oxygen-15 positron emission tomography (PET) and dynamic computed tomography. There were no grade 3 or 4 toxicities seen. Accrual is continuing at a dose of $600 \mathrm{mg} \cdot \mathrm{m}^{-2}$ [100].

Combretastatin. Combretastatin A-4 (CA4; OXiGENE Inc., Watertown, MA, USA) is a tubulin binding agent. It is an extract from the bark of the African bush willow, Combrestum caffrum, with a high therapeutic window and is selective for proliferating endothelial cells in vitro and induces vascular shutdown in tumour models in vivo [101]. An in vitro study of the CA4 prodrug showed a dose-dependent antiproliferative effect on human lung cell lines thought to be secondary to the disruption in microtubule assembly. In vivo, in human NSCLC murine xenografts, the CA4 prodrug significantly delayed growth of subcutaneously-induced lung cancer, which translated into a survival benefit [102].

In a recent phase I study, CA4 phosphate (CA4P) was administered by a weekly 10-min infusion for 3 weeks, followed by a gap in treatment of a week. The dose-limiting toxicity was reversible ataxia, vasovagal syncope and motor neuropathy. After 12 infusions, one patient had a partial response that was not maintained after a treatment break. It was concluded that CA4P was well tolerated in 11 of 13 patients at $52-68 \mathrm{mg} \cdot \mathrm{m}^{-2}$ and tumour blood flow reduction was reproducible at these doses [103]. Using dynamic, contrast-enhanced magnetic resonance imaging (MRI), the technique was shown to be reproducible, and $\mathrm{CA} 4 \mathrm{P}$ reduced kinetic blood flow in humans and animals at doses below the dose-limiting toxicity [104].

\section{Drugs that block activators of angiogenesis}

The anti-angiogenic agents that inhibit VEGF are described in the following paragraphs. Table 3 shows trials presently recruiting patients in the USA.

SU5416. SU5416 (SUGEN Inc., South San Francisco, CA, USA) is a selective inhibitor of VEGF-dependent phosphorylation of the VEGF receptor, Flk1/KDR, and the subsequent cell signalling downstream. It has been shown that despite a relatively short plasma half-life of $30 \mathrm{~min}$, prolonged inhibition of the receptor is seen with twice-weekly, or infrequent, dosing [105]. It is presently being assessed in the phase I setting alone, in combination with irinotecan and cisplatin in patients with solid tumours and in combination with paclitaxel in patients with advanced cancers. Thus far, the side-effects reported have been nausea, moderate vomiting, periorbital oedema and mild headache [106, 107].

SU6668. SU6668 (Sugen, Inc., South San Francisco, CA, USA) is a novel inhibitor of signal transduction via the Flk-1 VEGF receptor, FGF receptor and PDGF receptor. In preclinical testing, SU6668 resulted in significant growth inhibition of a variety of human tumour xenografts, including lung origin, following oral or intraperitoneal administration. Using 
Table 3. - Recent phase I and II studies of anti-vascular endothelial growth factor (VEGF) drugs recruiting in the USA

\begin{tabular}{|c|c|c|}
\hline Drug and trial & Tumour type & Target/mechanism \\
\hline \multicolumn{3}{|l|}{ SU5416 } \\
\hline Phase I & $\begin{array}{l}\text { With irinotecan and cisplatin against solid tumours } \\
\text { (temporarily closed, October 2001) }\end{array}$ & Blocks VEGF receptor signalling \\
\hline Phase I & With paclitaxel in advanced malignancies (active) & \\
\hline Phase I & In patients with advanced solid tumours (active) & \\
\hline \multicolumn{3}{|c|}{ P } \\
\hline Phase I & Advanced solid tumours (closed October 2001) & $\begin{array}{l}\text { Blocks VEGF, FGF, and } \\
\text { PDGF receptor signalling }\end{array}$ \\
\hline \multicolumn{3}{|l|}{ Anti-VEGF antibody } \\
\hline Phase I & $\begin{array}{l}\text { Relapsed or refractory progressive solid } \\
\text { tumours (closed September 2001) }\end{array}$ & $\begin{array}{l}\text { Monoclonal antibody to VEGF, } \\
\text { Bevacizumab }\end{array}$ \\
\hline Phase II/III & $\begin{array}{l}\text { Paclitaxel and carboplatin }+/ \text { - Bevacizumab } \\
\text { in advanced, metastatic or recurrent } \\
\text { non-squamous NSCLC (active) }\end{array}$ & \\
\hline Phase II & $\begin{array}{l}\text { Neoadjuvant Bevacizumab, paclitaxel and carboplatin } \\
\text { in stage IB, II or IIIA resectable NSCLC } \\
\text { (approved, not yet active) }\end{array}$ & \\
\hline
\end{tabular}

FGF: fibroblast growth factor; PDGF: platelet derived growth factor; NSCLC: nonsmall cell lung cancer. Manufacturer's details are as follows: SU5416: SUGEN, Inc., South San Francisco, CA, USA; SU6668: SUGEN, Inc.; Anti-VEGF antibody (Bevacizumab): Genentech, Inc., South San Francisco, CA, USA.

multifluorescence videomicroscopy, C6 glioma xenografts revealed that SU6668 suppressed angiogenesis [108]. A recent phase I clinical trial investigating SU6668 in patients with advanced solid tumours, found that mild-to-moderate side-effects occurred, including nausea, vomiting, fatigue and dyspnoea. Five of 68 patients remain in the study (median 13 weeks, range 2-86 weeks). One patient with NSCLC remains in the study with stable disease at 74 weeks [109].

Antivascular endothelial growth factor antibody. A phase I study of anti-VEGF antibody (humanized monoclonal IgG4k antibody (HuMV833); Protein Design Labs, Inc., Fremont, CA, USA), administered at doses of $0.3,1,3,10 \mathrm{mg} \cdot \mathrm{kg}^{-1}$ on days $1,15,22$ and 29, conducted under the auspices of the European Organization for Research and Treatment of Cancer (EORTC) Biological Treatment Development Group, has recently been published. Using contrast-enhanced MRI measurements, results showed that there was a $27-37 \%$ reduction in permeability at the first and third dose levels. Three patients maintained stable disease and no grade 3 toxicities were seen at the first two dose levels [110].

Another phase I study of anti-VEGF antibody (recombinant humanized monoclonal antibody to vascular endothelial growth factor receptor (rhuMAb VEGF)) performed in patients with advanced cancer, reported no grade 3 or 4 adverse events. Grade 1 and 2 toxicities included mild headache, asthenia and nausea. Three episodes of tumour-related bleeding were reported. No objective responses were seen, although 12 of $25(48 \%)$ patients maintained stable disease. Pharmacokinetics revealed a linear profile with a half-life of 21 days [111].

A phase Ib study of VEGF monoclonal antibody (rhuMAb VEGF) in combination with three chemotherapy regimens (doxorubicin $50 \mathrm{mg} \cdot \mathrm{m}^{-2}$ repeated every 4 weeks; carboplatin area under the curve multiplied by 6 (AUC6) plus paclitaxel $175 \mathrm{mg} \cdot \mathrm{m}^{-2}$ repeated every 4 weeks; and 5-fluorouracil $500 \mathrm{mg} \cdot \mathrm{m}^{-2}$ with leucovorin $20 \mathrm{mg} \cdot \mathrm{m}^{-2}$ weekly for 6 weeks and repeated every 8 weeks) $(n=12)$ concluded that the antibody could be safely combined with chemotherapy at doses associated with VEGF blockade and without apparent synergistic toxicity. The toxicities seen were diarrhoea (one of four in 5-fluorouracil arm), thrombocytopenia (two of four in the carboplatin/ paclitaxel arm) and leucopenia (one of four in the carboplatin/paclitaxel arm). Three responding patients were reported to be continuing on combination therapy without demonstrating cumulative or late toxicity [112].

Trastuzumab (Herceptin). As discussed previously, the EGFR is another target for anti-angiogenesis strategies. Studies investigating the role of the HER2-neu antibody (Trastuzumab, Herceptin; Genentech, Inc., South San Francisco, CA, USA) in the treatment of NSCLC are summarized in table 4.

The preliminary results of a phase II study of cisplatin and gemcitabine, combined with Herceptin in 12 patients with HER2-neu overexpressing NSCLC, showed that six patients had a partial response, five maintained stable disease and one progressed with therapy. Four patients remained on maintenance therapy 7 months later. The regimen was well tolerated, although the grade 3 toxicities reported were: neutropenia (six of 12), thrombocytopenia (five of 12), anaemia (two of 12), fatigue (two of 12) and nausea (one of 12). Grade 4 neutropenia was seen in four of 12 patients [113].

The preliminary results of a phase II trial combining paclitaxel $\left(225 \mathrm{mg} \cdot \mathrm{m}^{-2}\right)$ and carboplatin (AUC6) administered three weekly with Herceptin in HER2neu overexpressing NSCLC patients $(n=56 ; 139$ patients were screened) have recently been published. It was found that grade 3 (grade 4) toxicities were neutropenia $52 \%(29 \%)$ and thrombocytopenia $16 \%$ $(2 \%)$. An asymptomatic grade 2 fall in left ventricular 
Table 4. - Recent phase I, II and III trials of anti-epidermal growth factor receptor (EGFR) inhibitors recruiting in the USA

\begin{tabular}{ccc}
\hline Drug and trial & \multicolumn{1}{c}{ Tumour type } & Target/mechanism \\
\hline $\begin{array}{c}\text { Trastuzumab } \\
\text { (Herceptin) } \\
\text { Phase I }\end{array}$ & $\begin{array}{c}\text { IL-12+ Herceptin in HER2-neu overexpressing } \\
\text { malignancies (active) } \\
\text { With cisplatin and gemcitabine in stage IIIB+IV NSCLC } \\
\text { overexpressing HER2-neu (active) }\end{array}$ & $\begin{array}{c}\text { Recombinant humanized anti-HER2 } \\
\text { monoclonal antibody }\end{array}$ \\
Phase II & In stage IIIB+IV HER2-neu overexpressing NSCLC (active) & \\
Phase II & Gemcitabine and cisplatin +/- Iressa (ZD1839) in stage & Selective EGFR tyrosine \\
Iressa (ZD1839) & kinase inhibitor \\
Phase III & III+IV NSCLC (closed July 2001) & \\
Phase III & Paclitaxel and carboplatin +/- Iressa (ZD1839) in stage & \\
Phase III & IIIB+IV NSCLC (closed July 2001) & \\
& Cisplatin, etoposide, radiotherapy and docetaxel +/- Iressa & \\
\hline
\end{tabular}

IL-12: interleukin-12; HER2-neu: human epidermal growth factor receptor-2; NSCLC: nonsmall cell lung cancer; EGFR: epidermal growth factor receptor. Manufacturer's details are as follows: Trastuzumab (Herceptin): Genentech, Inc., South San Francisco, CA, USA; Iressa (ZD1839): AstraZeneca, London, UK.

ejection fraction was seen in $8 \%$ of patients. The nonhaematological toxicities were nausea, fatigue, arthralgia and peripheral neuropathy. Of the 44 evaluable patients, $18 \%$ responded to therapy with $15(34 \%)$ remaining on treatment, from which a projected survival was estimated to be 9.2 months [114].

Iressa (ZD1839). Iressa (ZD1839; AstraZeneca, London, UK) is a selective EGFR tyrosine kinase inhibitor. In vitro autophosphorylation of EGFR was prevented in the A549 nonsmall cell lung carcinoma cell line [115]. Co-administration of ZD1839 has been shown to enhance the efficacy of cytotoxic agents against human lung (SCLC and NSCLC) xenografts [116].

Iressa is orally active. Presently, there are four ongoing phase I trials assessing intermittent treatment and continuous daily dosing. It is generally well tolerated to a dose of $600 \mathrm{mg} \cdot \mathrm{day}^{-1}$. The most common adverse effects reported are skin rash, diarrhoea, nausea and vomiting. Preliminary results in NSCLC appear promising; in the phase I study with intermittent administration, 15 of $64(24 \%)$ patients achieved stable disease or responded for $>4$ months [117].

Presently, two multinational randomized, doubleblind, placebo-controlled phase III trials are ongoing in chemotherapy-naïve patients with advanced NSCLC in order to evaluate ZD1839. Iressa $\left(250 \mathrm{mg} \cdot \mathrm{day}^{-1}\right.$ or $500 \mathrm{mg} \cdot \mathrm{day}^{-1}$ ) will be given in combination with either gemcitabine/cisplatin or paclitaxel/carboplatin.
The primary end points are objective tumour response and disease-related symptom improvement, and the secondary objectives are tolerability and qualityof-life assessment [118].

\section{Drugs with a nonspecific mechanism of action affecting angiogenesis}

Carboxyamido-triazole (CAI) (National Cancer Institute, Bethesda, MD, USA) is an inhibitor of calcium-mediated signal transduction. In vitro, CAI produced downregulation of MMP-2 [119] and has been shown to inhibit tumour cell invasiveness [120, 121]. It is an oral drug that is presently undergoing phase I testing in solid tumours. A previous phase I study in 29 patients with advanced malignancies found the dose-limiting toxicity to be ataxia. Nausea and vomiting were problems to a lesser degree [122].

A randomized phase III study of CAI in advanced NSCLC (table 5) is presently active with the aims of assessing the safety and tolerability of oral CAI, evaluating quality of life and response rates in patients, and determining whether CAI prolongs the time to disease progression.

\section{Drugs that block breakdown of the extracellular matrix}

Both naturally-occurring and synthetic MMPs are undergoing clinical trials, either alone or in combination with chemotherapeutic agents. Those currently

Table 5.-Drugs with a nonspecific mechanism of action affecting angiogenesis recently under investigation in the USA

\begin{tabular}{lcc}
\hline Drug and trial & Tumour type & Target/mechanism \\
\hline $\begin{array}{l}\text { Carboxyamidotriazole } \\
\begin{array}{l}\text { Phase I } \\
\text { Phase III }\end{array}\end{array}$ & $\begin{array}{c}\text { With paclitaxel in advanced solid tumours or } \\
\text { refractory lymphomas (active) } \\
\text { In stage III and IV NSCLC (active) }\end{array}$ & Inhibitor of calcium influx \\
\hline
\end{tabular}

NSCLC: nonsmall cell lung cancer. Manufacturer's details for Carboxyamidotriazole are as follows: National Cancer Institute, Bethesda, MD, USA. 
Table 6. - Recent phase II and III studies of metalloproteinase inhibitors under investigation in the USA

\begin{tabular}{|c|c|c|}
\hline Drug and trial & Tumour type & Target/mechanism \\
\hline \multicolumn{3}{|l|}{ Marimastat } \\
\hline Phase III & $\begin{array}{l}\text { In SCLC following a response to first line } \\
\text { chemotherapy (active) }\end{array}$ & Synthetic inhibitor of MMPs \\
\hline COL-3 & & \\
\hline Phase I & Advanced solid tumours (active) & Oral MMP inhibitor \\
\hline $\begin{array}{l}\text { Neovastat (AE-941) } \\
\text { Phase III }\end{array}$ & $\begin{array}{l}\text { Induction platinum-based chemotherapy and } \\
\text { radiotherapy +/- AE-941 in stage IIIA or IIIB } \\
\text { unresectable NSCLC (active) }\end{array}$ & Naturally-occurring MMP inhibitor \\
\hline $\begin{array}{l}\text { BMS-275291 } \\
\text { Phase II/III }\end{array}$ & $\begin{array}{l}\text { Paclitaxel and carboplatin +/- BMS-275291 in } \\
\text { advanced or metastatic NSCLC (active) }\end{array}$ & Synthetic MMP inhibitor \\
\hline
\end{tabular}

under investigation for lung cancer are shown in table 6.

Marimastat. Marimastat (British Biotech plc, Oxford, UK) was the first orally-administered synthetic MMPI. Preclinical data for marimastat suggested reduction in tumour size and number of metastases [123]. The phase I study of marimastat, a broad spectrum MMPI, in advanced lung cancer, demonstrated that the drug had good oral bioavailability. The dose-limiting toxicity was cumulative severe polyarthritis, which was reversible following drug discontinuation [124].

Major phase II studies with marimastat have been performed in tumour types, which secreted plasma tumour markers, such as pancreatic, ovarian, prostate and colorectal tumours. Associations were determined between changes in the rate of rise of serum tumour markers with clinical outcome, suggesting that these changes may provide a valid surrogate end point [125-127].

Only one phase III trial, which randomized 414 patients with pancreatic cancer to treatment with gemcitabine or marimastat, has been published. Musculoskeletal toxicity was the main toxicity seen with the marimastat. No survival advantage was demonstrated, but marimastat was at least as efficacious as gemcitabine [128].

A randomized, double-blind, placebo-controlled phase III study of marimastat following response to first-line chemotherapy in patients with SCLC is still recruiting. The National Cancer Institute of Canada (NCIC)/EORTC phase III study of marimastat versus placebo in patients with SCLC closed in April 2000. Preliminary results of the 555 patients enrolled, with a median duration of follow-up of 20.4 months, demonstrated a median survival of 9.5 months, a 1 -yr survival of $38 \%$ and a 2 -yr survival of $20 \%$. There was a $12 \%$ rate of grade 3 and 4 musculoskeletal toxicity seen [129].

Neovastat (AE-941). Neovastat (AE-941; Aeterna Laboratories Inc., Quebec City, Quebec, Canada) is an oral, naturally-occurring MMPI derived from shark cartilage extract. It has been reported that in the Lewis lung carcinoma model, a $70 \%$ reduction in pulmonary metastases was observed and an additive effect was demonstrated when AE-941 was administered with cisplatin. During the phase I/II study, 80 patients with lung cancer received AE-941. There were no reports of serious adverse events and clinical improvements in analgesic use and weight gain were seen. No response was reported [130].

Prinomastat (AG3340). Prinomastat (AG3340; Agouron Pharmaceuticals Inc., La Jolla, CA, USA) is a synthetic hydroxamic acid derivative. It is a selective inhibitor of MMP-2, -3, -9 and -14. It has shown synergy in combination with chemotherapeutic agents. In a phase I study in combination with carboplatin and paclitaxel, AG3340 was well tolerated with only musculoskeletal side-effects [131]. Preliminary results of a randomized, placebocontrolled phase III study of AG3340 (5 mg, $10 \mathrm{mg}$, or $15 \mathrm{mg}$ ) or placebo in combination with paclitaxel $\left(200 \mathrm{mg} \cdot \mathrm{m}^{-2}\right.$ over $3 \mathrm{~h}$ ) and carboplatin (AUC6) repeated every 3 weeks in patients $(n=677)$ with advanced NSCLC demonstrated no difference between the treatment arms in overall survival, 1-yr survival, progression-free survival or response rate. The efficacy of the chemotherapy regimen was not enhanced by the addition of prinomastat [132].

BAY12-9566. BAY12-9566 (Bayer Corporation, Berkeley, CA, USA) is a butanoic acid analogue and is an oral-selective inhibitor of MMP-2 and MMP-9. The phase I data demonstrated a dosedependent hepatotoxicity and thrombocytopenia; no musculoskeletal side-effects were seen [133, 134]. The randomized, controlled phase III study of BAY12-9566 versus placebo, as maintenance therapy in patients with SCLC who had achieved a chemotherapy response, was prematurely closed when the preliminary results suggested a detrimental effect on survival in the SCLC group [135]. 


\section{Assessment of anti-angiogenic strategies}

The discovery of new potential anti-angiogenic and vascular targets and drugs has produced a plethora of clinical studies and trials investigating their activities, either alone or in combination with chemotherapy. However, it is anticipated that these drugs will have a prolonged administration and will act as cytostatic agents, slowing the rate of disease progression or maintaining disease stabilization. The advent of these targeted drugs provides an opportunity to revise drug trial design methodology to accurately assess standard and surrogate measures of drug activity and efficacy.

The toxicity profiles of these drugs are relevant, but may be more varied than standard chemotherapy agents. The maximum tolerated dose (MTD) may occur at a much higher dose than that required for an anti-angiogenic agent to stop neovascularization. It has been suggested that an optimal biological dose, for which effective target inhibition is attained without noticeable toxicity, may be a more suitable end point than MTD [136].

Subtle changes may arise secondary to antiangiogenic drug activity, making response assessment more difficult than for standard chemotherapies. This may mean that tumour response to therapy as an end point may be inappropriate, although it should still be measured clinically and with imaging. As a result, the outcome measures of time to tumour progression and overall survival may be of greater importance for assessing these agents, which are felt to be cytostatic. The standard methods currently utilized to assess tumour response to therapy may, therefore, not be the best or the most meaningful for these strategies.

Surrogate end points need to be derived, investigated and validated alongside standard response and toxicity criteria. It has been shown that IMD is of prognostic importance, but serial measurement of IMD with the administration of an anti-angiogenic drug would require repeated tumour biopsy. This is not only difficult to perform, but also ethically and psychologically difficult to justify. Functional imaging techniques, such as Doppler ultrasound, functional MRI and PET can provide in vivo noninvasive data regarding the tumour and normal vascular blood flow. PET can also provide in vivo data regarding tumour proliferation and metabolism.

As discussed previously, serum, urine and BALF concentrations of growth factors can be measured. Similarly, using serial measurements, the rate of change in tumour marker concentrations may provide a surrogate measure of anti-angiogenic drug efficacy. These should be explored further and validated.

The design of new studies and trials investigating these agents must, therefore, utilize and assess surrogate measures of response as well as standard anatomical imaging and clinical toxicity scores in order to validate their role for monitoring tumour response to anti-angiogenic agents. A number of the agents presently under investigation are being assessed in advanced and metastatic disease. However, they may also have a role at a much earlier time-point in the disease; for example, either starting in the neoadjuvant phase or as maintenance therapy following curative resection in early stage nonsmall cell lung cancer, since an anti-angiogenic agent may prevent neo-angiogenesis, tumour relapse and metastasis. This is a great challenge in the future of drug development and anticancer therapies.

\section{References}

1. Mortality Statistics: Cause. Review by Registrar General on deaths by cause, sex and age, in England and Wales. National Statistics, series DH2, No. 26. London, The Stationery Office, 1999.

2. Howe HL, Wingo PA, Thun MJ, et al. Annual report to the nation on the status of cancer (1973 through 1998), featuring cancers with recent increasing trends. J Natl Cancer Inst 2001; 93: 824-842.

3. Dwamena BA, Sonnad SS, Angobaldo JO, Wahl RL. Metastases from non-small cell lung cancer: mediastinal staging in the 1990s meta-analytic comparison of PET and CT. Radiology 1999; 213: 530-536.

4. Laking G, Price P. 18-Fluorodeoxyglucose positron emission tomography (FDG-PET) and the staging of early lung cancer. Thorax 2001; 56: Suppl. 2, 38-44.

5. Salminen E, MacManus M. Impact of FDG-labelled positron emission tomography imaging on the management of non-small-cell lung cancer. Ann Med 2001; 33: $404-409$.

6. Folkman J. Tumor angiogenesis: therapeutic implications. N Engl J Med 1971; 285: 1182-1186.

7. $\mathrm{O}^{\prime}$ Reilly MS, Holmgren L, Shing Y, et al. Angiostatin: a novel angiogenesis inhibitor that mediates the suppression of metastases by a Lewis lung carcinoma. Cell 1994; 79: 315-328.

8. DeMoraes ED, Fogler WE, Grant D, et al. Recombinant human angiostatin (rhA): a Phase I clinical trial assessing safety, pharmacokinetics (pk) and pharmacodynamics (pd). Proc Am Soc Clin Oncol 2001; 20: $3 a$.

9. Volm M, Mattern J, Koomagi R. Angiostatin expression in non-small cell lung cancer. Clin Cancer Res 2000; 6: 3236-3240.

10. O'Reilly MS, Boehm T, Shing Y, et al. Endostatin: an endogenous inhibitor of angiogenesis and tumor growth. Cell 1997; 88: 277-285.

11. Chalkley HW. Method for the quantitative morphological analysis of tissues. J Natl Canc Inst 1943; 4: 4753.

12. Vermeulen PB, Gasparini G, Fox SB, et al. Quantification of angiogenesis in solid human tumours: an international consensus on the methodology and criteria of evaluation. Eur J Cancer 1996; 32A: 2474 2484.

13. Toi M, Kashitani J, Tominaga T. Tumor angiogenesis is an independent prognostic indicator in primary breast carcinoma. Int J Cancer 1993; 55: 371-374.

14. Fox SB, Leek RD, Smith K, Hollyer J, Greenall M, Harris AL. Tumor angiogenesis in node-negative breast carcinomas-relationship with epidermal growth factor receptor, estrogen receptor, and survival. Breast Cancer Res Treat 1994; 29: 109-116.

15. Hansen S, Grabau DA, Sorensen FB, Bak M, Vach $\mathrm{W}$, Rose C. The prognostic value of angiogenesis by Chalkley counting in a confirmatory study design on 836 breast cancer patients. Clin Cancer Res 2000; 6: 139-146. 
16. Dickinson AJ, Fox SB, Persad RA, Hollyer J, Sibley GN, Harris AL. Quantification of angiogenesis as an independent predictor of prognosis in invasive bladder carcinomas. Br J Urol 1994; 74: 762-766.

17. Weidner N, Semple JP, Welch WR, Folkman J. Tumor angiogenesis and metastasis-correlation in invasive breast carcinoma. $N$ Engl J Med 1991; 324: $1-8$.

18. Takahashi Y, Kitadai Y, Bucana CD, Cleary KR, Ellis LM. Expression of vascular endothelial growth factor and its receptor, KDR, correlates with vascularity, metastasis, and proliferation of human colon cancer. Cancer Res 1995; 55: 3964-3968.

19. Weidner N, Carroll PR, Flax J, Blumenfeld W, Folkman J. Tumor angiogenesis correlates with metastasis in invasive prostate carcinoma. Am J Pathol 1993; 143: 401-409.

20. Fontanini G, Lucchi M, Vignati S, et al. Angiogenesis as a prognostic indicator of survival in non-small-cell lung carcinoma: a prospective study. J Natl Cancer Inst 1997; 89: 881-886.

21. Matsuyama K, Chiba Y, Sasaki M, Tanaka H, Muraoka R, Tanigawa N. Tumor angiogenesis as a prognostic marker in operable non-small cell lung cancer. Ann Thorac Surg 1998; 65: 1405-1409.

22. Dazzi C, Cariello A, Maioli P, et al. Prognostic and predictive value of intratumoral microvessels density in operable non-small-cell lung cancer. Lung Cancer 1999; 24: 81-88.

23. Cox G, Walker RA, Andi A, Steward WP, O'Byrne KJ. Prognostic significance of platelet and microvessel counts in operable non-small cell lung cancer. Lung Cancer. 2000; 29: 169-177.

24. Macchiarini P, Fontanini G, Hardin MJ, Squartini F, Angeletti CA. Relation of neovascularisation to metastasis of non-small-cell lung cancer. Lancet 1992; 340: 145-146.

25. Chandrachud LM, Pendleton N, Chisholm DM, Horan MA, Schor AM. Relationship between vascularity, age and survival in non-small-cell lung cancer. Br J Cancer 1997; 76: 1367-1375.

26. Pezzella F, Pastorino U, Tagliabue E, et al. Nonsmall-cell lung carcinoma tumor growth without morphological evidence of neo-angiogenesis. Am J Pathol 1997; 151: 1417-1423.

27. Lund EL, Thorsen C, Pedersen MW, Junker N, Kristjansen PE. Relationship between vessel density and expression of vascular endothelial growth factor and basic fibroblast growth factor in small cell lung cancer in vivo and in vitro. Clin Cancer Res 2000; 6: 4287-4291.

28. Cherrington JM, Strawn LM, Shawver LK. New paradigms for the treatment of cancer: the role of anti-angiogenesis agents. Adv Cancer Res 2000; 79: $1-38$.

29. Grugel S, Finkenzeller G, Weindel K, Barleon B, Marme D. Both v-Ha-Ras and v-Raf stimulate expression of the vascular endothelial growth factor in NIH 3T3 cells. J Biol Chem 1995; 270: 25915-25919.

30. Rak J, Mitsuhashi Y, Bayko L, et al. Mutant ras oncogenes upregulate VEGF/VPF expression: implications for induction and inhibition of tumor angiogenesis. Cancer Res 1995; 55: 4575-4580.

31. Mukhopadhyay D, Tsiokas L, Sukhatme VP. Wild-type p53 and v-Src exert opposing influences on human vascular endothelial growth factor gene expression. Cancer Res 1995; 55: 6161-6165.
32. Marconcini L, Marchio S, Morbidelli L, et al. c-fos-induced growth factor/vascular endothelial growth factor D induces angiogenesis in vivo and in vitro. Proc Natl Acad Sci USA 1999; 96: 9671-9676.

33. Yen L, You XL, Al Moustafa AE, et al. Heregulin selectively upregulates vascular endothelial growth factor secretion in cancer cells and stimulates angiogenesis. Oncogene 2000; 19: 3460-3469.

34. Shweiki D, Ahuva I, Soffer D, Keshet E. Vascular endothelial growth factor induced by hypoxia may mediate hypoxia-initiated angiogenesis. Nature 1992; 359: 843-845.

35. Pertovaara L, Kaipainen A, Mustonen $\mathrm{T}$, et al. Vascular endothelial growth factor is induced in response to transforming growth factor-beta in fibroblastic and epithelial cells. J Biol Chem 1994; 269: 6271-6274.

36. Yuan A, Yu CJ, Kuo SH, et al. Vascular endothelial growth factor $189 \mathrm{mRNA}$ isoform expression specifically correlates with tumor angiogenesis, patient survival, and postoperative relapse in non-small-cell lung cancer. J Clin Oncol 2001; 19: 432-441.

37. Toi M, Inada K, Suzuki H, Tominaga T. Tumor angiogenesis in breast cancer: its importance as a prognostic indicator and the association with vascular endothelial growth factor expression. Breast Cancer Res Treat 1995; 36: 193-204.

38. Maeda K, Chung YS, Ogawa Y, et al. Prognostic value of vascular endothelial growth factor expression in gastric carcinoma. Cancer 1996; 77: 858-863.

39. Strohmeyer D, Rossing C, Bauerfeind A, et al. Vascular endothelial growth factor and its correlation with angiogenesis and p53 expression in prostate cancer. Prostate 2000; 45: 216-224.

40. Mineta H, Miura K, Ogino T, et al. Prognostic value of vascular endothelial growth factor (VEGF) in head and neck squamous cell carcinomas. Br J Cancer 2000; 83: 775-781.

41. Shen GH, Ghazizadeh M, Kawanami O, et al. Prognostic significance of vascular endothelial growth factor expression in human ovarian carcinoma. $\mathrm{Br}$ $J$ Cancer 2000; 83: 196-203.

42. Seo Y, Baba H, Fukuda T, Takashima M, Sugimachi K. High expression of vascular endothelial growth factor is associated with liver metastasis and a poor prognosis for patients with ductal pancreatic adenocarcinoma. Cancer 2000; 88: 2239-2245.

43. Yudoh K, Kanamori M, Ohmori K, Yasuda T, Aoki M, Kimura T. Concentration of vascular endothelial growth factor in the tumour tissue as a prognostic factor of soft tissue sarcomas. Br J Cancer 2001; 84: $1610-1615$.

44. Mattern J, Koomagi R, Volm M. Association of vascular endothelial growth factor expression with intratumoral microvessel density and tumour cell proliferation in human epidermoid lung carcinoma. Br J Cancer 1996; 73: 931-934.

45. Fontanini G, Boldrini L, Chine S, et al. Expression of vascular endothelial growth factor mRNA in nonsmall-cell lung carcinomas. Br J Cancer 1999; 79: 363369.

46. O'Byrne KJ, Koukourakis MI, Giatromanolaki A, et al. Vascular endothelial growth factor, plateletderived endothelial cell growth factor and angiogenesis in non-small-cell lung cancer. $\mathrm{Br} J$ Cancer 2000; 82: 1427-1432.

47. Han H, Silverman JF, Santucci TS, et al. Vascular 
endothelial growth factor expression in stage I nonsmall cell lung cancer correlates with neoangiogenesis and a poor prognosis. Ann Surg Oncol 2001; 8: 72-79.

48. Ohta Y, Tomita Y, Oda M, Watanabe S, Murakami S, Watanabe $Y$. Tumor angiogenesis and recurrence in stage I non-small cell lung cancer. Ann Thorac Surg 1999; 68: 1034-1038.

49. Baillie R, Carlile J, Pendleton N, Schor AM. Prognostic value of vascularity and vascular endothelial growth factor expression in non-small cell lung cancer. $J$ Clin Pathol 2001; 54: 116-120.

50. Matsuyama W, Hashiguchi T, Mizoguchi A, et al. Serum levels of vascular endothelial growth factor dependent on the stage progression of lung cancer. Chest 2000; 118: 948-951.

51. Salven P, Ruotsalainen T, Mattson K, Joensuu H. High pre-treatment serum level of vascular endothelial growth factor (VEGF) is associated with poor outcome in small-cell lung cancer. Int J Cancer 1998; 79: 144-146.

52. Brattstrom D, Bergqvist M, Larsson A, et al. Basic fibroblast growth factor and vascular endothelial growth factor in sera from non-small cell lung cancer patients. Anticancer Res 1998; 18: 1123-1127.

53. Beinert T, Binder D, Oehm C, et al. Increased levels of vascular endothelial growth factor in bronchoalveolar lavage of patients with bronchial carcinoma effect of tumour activity and oxidative stress due to radiochemotherapy? Eur J Med Res 1999; 4: 328-334.

54. Heldin $\mathrm{CH}$. Structural and functional studies on platelet-derived growth factor. EMBO $J$ 1992; 11: 4251-4259.

55. Antoniades HN, Galanopoulos T, Neville-Golden J, $\mathrm{O}^{\prime}$ Hara CJ. Malignant epithelial cells in primary human lung carcinomas coexpress in vivo plateletderived growth factor (PDGF) and PDGF receptor mRNAs and their protein products. Proc Natl Acad Sci USA 1992; 89: 3942-3946.

56. Hermanson M, Funa K, Hartman M, et al. Plateletderived growth factor and its receptors in human glioma tissue: expression of messenger RNA and protein suggests the presence of autocrine and paracrine loops. Cancer Res 1992; 52: 3213-3219.

57. Seymour L, Bezwoda WR. Positive immunostaining for platelet derived growth factor (PDGF) is an adverse prognostic factor in patients with advanced breast cancer. Breast Cancer Res Treat 1994; 32: 229233.

58. Sato TN, Tozawa Y, Deutsch U, et al. Distinct roles of the receptor tyrosine kinases Tie-1 and Tie-2 in blood vessel formation. Nature 1995; 376: 70-74.

59. Maisonpierre PC, Suri C, Jones PF, et al. Angiopoietin-2, a natural antagonist for Tie2 that disrupts in vivo angiogenesis. Science 1997; 277: 55-60.

60. Takahama $\mathrm{M}$, Tsutsumi $\mathrm{M}$, Tsujiuchi $\mathrm{T}$, et al. Enhanced expression of Tie2, its ligand angiopoietin1, vascular endothelial growth factor, and CD31 in human non-small cell lung carcinomas. Clin Cancer Res 1999; 5: 2506-2510.

61. Wong MP, Chan SY, Fu KH, et al. The angiopoietins, tie 2 and vascular endothelial growth factor are differentially expressed in the transformation of normal lung to non-small cell lung carcinomas. Lung Cancer 2000; 29: 11-22.

62. Moghaddam A, Bicknell R. Expression of plateletderived endothelial cell growth factor in Escherichia coli and confirmation of its thymidine phosphorylase activity. Biochemistry 1992; 31: 12141-12146.

63. Brown NS, Jones A, Fujiyama C, Harris AL, Bicknell $\mathrm{R}$. Thymidine phosphorylase induces carcinoma cell oxidative stress and promotes secretion of angiogenic factors. Cancer Res 2000; 60: 6298-6302.

64. Moghaddam A, Zhang HT, Fan TP, et al. Thymidine phosphorylase is angiogenic and promotes tumor growth. Proc Natl Acad Sci USA 1995; 92: 998-1002.

65. Fox SB, Westwood $\mathrm{M}$, Moghaddam A, et al. The angiogenic factor platelet-derived endothelial cell growth factor/thymidine phosphorylase is upregulated in breast cancer epithelium and endothelium. Br J Cancer 1996; 73: 275-280.

66. $\mathrm{O}^{\prime}$ Brien TS, Fox SB, Dickinson AJ, et al. Expression of the angiogenic factor thymidine phosphorylase/ platelet-derived endothelial cell growth factor in primary bladder cancers. Cancer Res 1996; 56: 4799 4804.

67. Giatromanolaki A, Koukourakis MI, Kakolyris S, et al. Focal expression of thymidine phosphorylase associates with CD31 positive lymphocytic aggregation and local neo-angiogenesis in non-small cell lung cancer. Anticancer Res 1998; 18: 71-76.

68. van Triest B, Pinedo HM, Blaauwgeers JL, et al. Prognostic role of thymidylate synthase, thymidine phosphorylase/platelet-derived endothelial cell growth factor, and proliferation markers in colorectal cancer. Clin Cancer Res 2000; 6: 1063-1072.

69. Arima J, Imazono Y, Takebayashi Y, et al. Expression of thymidine phosphorylase as an indicator of poor prognosis for patients with transitional cell carcinoma of the bladder. Cancer 2000; 88: 1131-1138.

70. Koukourakis MI, Giatromanolaki A, O'Byrne KJ, et al. Platelet-derived endothelial cell growth factor expression correlates with tumour angiogenesis and prognosis in non-small-cell lung cancer. $B r J$ Cancer 1997; 75: 477-481.

71. Yamashita J, Ogawa M, Abe M, Nishida M. Plateletderived endothelial cell growth factor/thymidine phosphorylase concentrations differ in small cell and non-small cell lung cancer. Chest 1999; 116: 206-211.

72. Berger W, Setinek U, Mohr T, et al. Evidence for a role of FGF-2 and FGF receptors in the proliferation of non-small cell lung cancer cells. Int J Cancer 1999; 83: 415-423.

73. Strizzi L, Vianale G, Catalano A, Muraro R, Mutti L, Procopio A. Basic fibroblast growth factor in mesothelioma pleural effusions: correlation with patient survival and angiogenesis. Int J Oncol 2001; 18: 1093-1098.

74. Volm M, Koomagi R, Mattern J, Stammler G. Prognostic value of basic fibroblast growth factor and its receptor (FGFR-1) in patients with non-small cell lung carcinomas. Eur J Cancer 1997; 33: 691-693.

75. Ueno K, Inoue Y, Kawaguchi T, Hosoe S, Kawahara $M$. Increased serum levels of basic fibroblast growth factor in lung cancer patients: relevance to response of therapy and prognosis. Lung Cancer 2001; 31: 213219.

76. Velu TJ. Structure, function and transforming potential of the epidermal growth factor receptor. Mol Cell Endocrinol 1990; 70: 205-216.

77. Hernandez-Sotomayor SM, Carpenter G. Epidermal growth factor receptor: elements of intracellular communication. J Membr Biol 1992; 128: 81-89.

78. de Jong JS, van Diest PJ, van der Valk P, Baak JP. 
Expression of growth factors, growth-inhibiting factors, and their receptors in invasive breast cancer. II: Correlations with proliferation and angiogenesis. J Pathol 1998; 184: 53-57.

79. Tsai JC, Goldman CK, Gillespie GY. Vascular endothelial growth factor in human glioma cell lines: induced secretion by EGF, PDGF-BB, and bFGF. J Neurosurg 1995; 82: 864-873.

80. Eissa S, Khalifa A, el-Gharib A, Salah N, Mohamed MK. Multivariate analysis of DNA ploidy, p53, c-erbB-2 proteins, EGFR, and steroid hormone receptors for short-term prognosis in breast cancer. Anticancer Res 1997; 17: 3091-3097.

81. Giatromanolaki A, Koukourakis MI, O'Byrne K, et al. Non-small cell lung cancer: c-erbB-2 overexpression correlates with low angiogenesis and poor prognosis. Anticancer Res 1996; 16: 3819-3825.

82. Brabender $\mathrm{J}$, Danenberg $\mathrm{KD}$, Metzger $\mathrm{R}$, et al. Epidermal growth factor receptor and HER2-neu mRNA expression in non-small cell lung cancer is correlated with survival. Clin Cancer Res 2001; 7: 1850-1855.

83. Reinmuth N, Brandt B, Kunze WP, et al. Ploidy, expression of erbB1, erbB2, P53 and amplification of erbB1, erbB2 and erbB3 in non-small cell lung cancer. Eur Respir J 2000; 16: 991-996.

84. Rusch V, Klimstra D, Venkatraman E, Pisters PW, Langenfeld J, Dmitrovsky E. Overexpression of the epidermal growth factor receptor and its ligand transforming growth factor alpha is frequent in resectable non-small cell lung cancer but does not predict tumor progression. Clin Cancer Res 1997; 3: 515-522.

85. Nelson AR, Fingleton B, Rothenberg ML, Matrisian LM. Matrix metalloproteinases: biologic activity and clinical implications. J Clin Oncol 2000; 18: 11351149.

86. Taraboletti G, Garofalo A, Belotti D, et al. Inhibition of angiogenesis and murine hemangioma growth by batimastat, a synthetic inhibitor of matrix metalloproteinases. J Natl Cancer Inst 1995; 87: 293-298.

87. Enenstein J, Waleh NS, Kramer RH. Basic FGF and TGF-beta differentially modulate integrin expression of human microvascular endothelial cells. Exp Cell Res 1992; 203: 499-503.

88. Brooks PC, Clark RA, Cheresh DA. Requirement of vascular integrin alpha $\mathrm{v}$ beta 3 for angiogenesis. Science 1994; 264: 569-571.

89. Gutheil JC, Campbell TN, Pierce PR, et al. Targeted antiangiogenic therapy for cancer using Vitaxin: a humanized monoclonal antibody to the integrin alphavbeta3. Clin Cancer Res 2000; 6: 3056-3061.

90. Carter SK. Clinical strategy for the development of angiogenesis inhibitors. Oncologist 2000; 5: 51-54.

91. Denekamp J, Dasu A, Waites A. Vasculature and microenvironmental gradients: the missing links in novel approaches to cancer therapy? Adv Enzyme Regul 1998; 38: 281-299.

92. D'Amato RJ, Loughnan MS, Flynn E, Folkman J. Thalidomide is an inhibitor of angiogenesis. Proc Natl Acad Sci USA 1994; 91: 4082-4085.

93. Minchinton AI, Fryer KH, Wendt KR, Clow KA, Hayes MM. The effect of thalidomide on experimental tumors and metastases. Anticancer Drugs 1996; 7: 339343.

94. Little RF, Wyvill KM, Pluda JM, et al. Activity of thalidomide in AIDS-related Kaposi's sarcoma. $J$ Clin Oncol 2000; 18: 2593-2602.
95. Fine HA, Figg WD, Jaeckle K, et al. Phase II trial of the antiangiogenic agent thalidomide in patients with recurrent high-grade gliomas. J Clin Oncol 2000; 18: 708-715.

96. Teicher BA, Williams JI, Takeuchi H, Ara G, Herbst RS, Buxton D. Potential of the aminosterol, squalamine in combination therapy in the rat 13,762 mammary carcinoma and the murine Lewis lung carcinoma. Anticancer Res 1998; 18: 2567-2573.

97. Schiller JH, Bittner G. Potentiation of platinum antitumor effects in human lung tumor xenografts by the angiogenesis inhibitor squalamine: effects on tumor neovascularization. Clin Cancer Res 1999; 5: 4287-4294.

98. Patnaik A, Rowinsky E, Hammond L, et al. A phase I and pharmacokinetic (PK) study of the unique angiogenesis inhibitor, squalamine lactate (MSI-1256F). Proc Am Soc Clin Oncol 1999; 18: 162a.

99. Bhargava P, Trocky N, Marshall J, et al. A phase I safety, tolerance and pharmacokinetic study of rising dose, rising duration continuous infusion of MSI$1256 \mathrm{~F}$ (squalamine lactate) in patients with advanced cancer. Proc Am Soc Clin Oncol 1999; 18: 162a.

100. Herbst RS, Tran HT, Mullani NA, et al. Phase I clinical trial of recombinant human endostatin (rhE) in patients (Pts) with solid tumour: pharmacokinetics (pk), safety and efficacy analysis using surrogate endpoints of tissue and radiologic response. Proc Am Soc Clin Oncol 2001; 20: 3a.

101. Iyer S, Chaplin DJ, Rosenthal DS, Boulares AH, $\mathrm{Li}$ LY, Smulson ME. Induction of apoptosis in proliferating human endothelial cells by the tumorspecific antiangiogenesis agent combretastatin A-4. Cancer Res 1998; 58: 4510-4514.

102. Boehle AS, Sipos B, Kliche U, Kalthoff H, Dohrmann P. Combretastatin A-4 prodrug inhibits growth of human non-small cell lung cancer in a murine xenotransplant model. Ann Thorac Surg 2001; 71: 1657-1665.

103. Rustin GJ, Price P, Stratford M, et al. Phase I study of weekly intravenous combretastain A4 phosphate (CA4P) pharmacokinetics and toxicity. Proc Am Soc Clin Oncol 2001; 20: 99a.

104. Galbraith SM, Lodge MA, Taylor NJ, et al. Combretastin A4 Phosphate (CA4P) reduces tumor blood flow in animals and man, demonstrated by MRI. Proc Am Soc Clin Oncol 2001; 20: 70a.

105. Mendel DB, Schreck RE, West DC, et al. The angiogenesis inhibitor SU5416 has long-lasting effects on vascular endothelial growth factor receptor phosphorylation and function. Clin Cancer Res 2000; 6: 4848-4858.

106. Salzberg M, Pless M, Rochlitz C, et al. A phase I and pharmacokinetic study of a single oral administration of SU5416 in patients with advanced solid tumors. Proc Am Soc Clin Oncol 2001; 20: 98a.

107. Rosen PJ, Kabbinavar F, Figlin RA, et al. A phase I/II trial and pharmacokinetic (pk) study of SU5416 in combination with paclitaxel and carboplatin. Proc Am Soc Clin Oncol 2001; 20: 98a.

108. Laird AD, Vajkoczy P, Shawver LK, et al. SU6668 is a potent antiangiogenic and antitumor agent that induces regression of established tumors. Cancer Res 2000; 60: 4152-4160.

109. Rosen LS, Rosen PJ, Kabbinavar F, et al. Phase I experiment with SU6668, a novel multiple receptor 
tyrosine kinase inhibitor in patients with advanced malignancies. Proc Am Soc Clin Oncol 2001; 20: 97a.

110. Jayson GC, Mulatero C, Ranson M, et al. Anti VEGF antibody HuMV833: an EORTC Biological Treatment Development Group phase I toxicity, pharmacokinetic and pharmacodynamic study. Proc Am Soc Clin Oncol 2001; 20: 4a.

111. Gordon MS, Margolin K, Talpaz M, et al. Phase I safety and pharmacokinetic study of recombinant human anti-vascular endothelial growth factor in patients with advanced cancer. J Clin Oncol 2001; 19: 843-850.

112. Margolin K, Gordon MS, Holmgren E, et al. Phase Ib trial of intravenous recombinant humanized monoclonal antibody to vascular endothelial growth factor in combination with chemotherapy in patients with advanced cancer: pharmacologic and long-term safety data. J Clin Oncol 2001; 19: 851-856.

113. Zinner RG, Glisson BS, Pisters KM, et al. Cisplatin and Gemcitabine combined with Herceptin in patients (Pts) with HER 2 overexpressing, untreated, advanced non-small-cell lung cancer (NSCLC): a phase II trial. Proc Am Soc Clin Oncol 2001; 20: 328a.

114. Langer CJ, Adak S, Thor A, Vangel M, Johnson D. Phase II Eastern Co-operative Oncology Group (ECOG) pilot study of paclitaxel (P), carboplatin (C) and Trastuzimab (T) in HER2/neu (+) advanced nonsmall cell lung cancer (NSCLC): early analysis of E2598. Proc Am Soc Clin Oncol 2001; 20: 315a.

115. Woodburn JR, Barker AJ, Wakeling AE, Valcaccia BE, Cartlidge SA, Davies DH. 6-amino-4-(3methylphenylamino)-quinazolone: an EGF receptor kinase inhibitor with activity in a range of human tumour xenografts. Proc Am Assoc Canc Res 1996; 37: 390.

116. Sirotnak FM, Zakowski MF, Miller VA, Scher HI, Kris MG. Efficacy of cytotoxic agents against human tumor xenografts is markedly enhanced by coadministration of ZD1839 (Iressa), an inhibitor of EGFR tyrosine kinase. Clin Cancer Res 2000; 6: 4885-4892.

117. Ferry D, Hammond L, Ranson M, et al. Intermittent oral ZD1839 (Iressa), a novel epidermal growth factor receptor tyrosine kinase inhibitor (EGFR-TKI), shows evidence of good tolerability and activity: final results from a Phase I study. Proc Am Soc Clin Oncol 2000; 19: $3 \mathrm{a}$.

118. Baselga J, Averbuch SD. ZD1839 ('Iressa') as an anticancer agent. Drugs 2000; 60: Suppl. 1, 33-40.

119. Kohn EC, Jacobs W, Kim YS, Alessandro R, StetlerStevenson WG, Liotta LA. Calcium influx modulates expression of matrix metalloproteinase-2 (72-kDa type IV collagenase, gelatinase A). $J$ Biol Chem 1994; 269 : 21505-21511.

120. Lambert PA, Somers KD, Kohn EC, Perry RR. Antiproliferative and antiinvasive effects of carboxyamidotriazole on breast cancer cell lines. Surgery 1997; 122: 372-378.

121. Jacobs W, Mikkelsen T, Smith R, Nelson K, Rosenblum ML, Kohn EC. Inhibitory effects of CAI in glioblastoma growth and invasion. J Neurooncol 1997; 32: 93-101.

122. Berlin J, Tutsch KD, Hutson $\mathrm{P}$, et al. Phase I clinical and pharmacokinetic study of oral carboxyamidotriazole, a signal transduction inhibitor. $J$ Clin Oncol 1997; 15: 781-789.
123. Wojtowicz-Praga SM, Dickson RB, Hawkins MJ. Matrix metalloproteinase inhibitors. Invest New Drugs 1997; 15: 61-75.

124. Wojtowicz-Praga S, Torri J, Johnson M, et al. Phase I trial of Marimastat, a novel matrix metalloproteinase inhibitor, administered orally to patients with advanced lung cancer. J Clin Oncol 1998; 16: 21502156.

125. Nemunaitis J, Poole C, Primrose J, et al. Combined analysis of studies of the effects of the matrix metalloproteinase inhibitor marimastat on serum tumor markers in advanced cancer: selection of a biologically active and tolerable dose for longer-term studies. Clin Cancer Res 1998; 4: 1101-1109.

126. Primrose JN, Bleiberg H, Daniel F, et al. Marimastat in recurrent colorectal cancer: exploratory evaluation of biological activity by measurement of carcinoembryonic antigen. Br J Cancer 1999; 79: 509-514.

127. Watson SA, Morris TM, Collins HM, Bawden LJ, Hawkins K, Bone EA. Inhibition of tumour growth by marimastat in a human xenograft model of gastric cancer: relationship with levels of circulating CEA. $\mathrm{Br}$ J Cancer 1999; 81: 19-23.

128. Bramhall SR, Rosemurgy A, Brown PD, Bowry C, Buckels JA. Marimastat Pancreatic Cancer Study Group. Marimastat as first-line therapy for patients with unresectable pancreatic cancer: a randomized trial. J Clin Oncol 2001; 19: 3447-3455.

129. Shepherd FA, Giaccone G, Debruyne C, et al. Randomized double-blind placebo-controlled trial of marimastat in patients with small cell lung cancer (SCLC) following response to first-line chemotherapy: an NCIC-CTG and EORTC study. Proc Am Soc Clin Oncol 2001; 20: 49a.

130. Evans WK, Latreille J, Batist G, et al. AE-941, an inhibitor of angiogenesis: rationale for development in combination with induction chemotherapy/radiotherapy in patients with non small cell lung cancer (NSCLC). Proc Am Soc Clin Oncol 1999; 18: 502a.

131. D'Olimpio J, Hande K, Collier M, Michelson G, Paradiso L, Clendeninn N. Phase I study of the matrix metalloproteinase inhibitor AG3340 in combination with paclitaxel and carboplatin for the treatment of patients with advanced solid tumours. Proc Am Soc Clin Oncol 1999; 18: 160a.

132. Smylie M, Mercier R, Aboulafia D, et al. Phase III study of the matrix metalloproteinase (MMP) inhibitor Prinomastat in patients having advanced non-small cell lung cancer (NSCLC). Proc Am Soc Clin Oncol 2001; 20: 307a.

133. Grochow L, O'Reilly S, Humphrey R, et al. Phase I and pharmacokinetic study of the matrix metalloproteinase inhibitor (MMP), Bay12-9566. Proc Am Soc Clin Oncol 1998; 17: 213a.

134. Goel R, Hirte H, Major P, et al. Clinical pharmacology of the metalloproteinase (MMP) and angiogenesis inhibitor Bayer 12-9566 in cancer patients. Proc Am Soc Clin Oncol 1999; 18: 160a.

135. Hidalgo M, Eckhardt SG. Development of matrix metalloproteinase inhibitors in cancer therapy. $J$ Natl Cancer Inst 2001; 93: 178-193.

136. Deplanque G, Harris AL. Anti-angiogenic agents: clinical trial design and therapies in development. Eur $J$ Cancer 2000; 36: 1713-1724. 